\title{
Synthesis and Structural Characterization of a Highly Effective Chiral Dipyridylphosphine Ligand and Its Application in the Ru-Catalyzed Asymmetric Hydrogenation of $\beta$-Ketoesters
}

\author{
Jing Wu, Hua Chen, Zhong-Yuan Zhou, Chi Hung Yeung, Albert S. C. Chan* \\ Open Laboratory of Chirotechnology and Department of Applied Biology and Chemical Technology, The Hong Kong Polytechnic \\ University, Hong Kong
}

Fax +852 23649932; E-mail: bcachan@polyu.edu.hk

Received 1 April 2001

\begin{abstract}
A new chiral dipyridylphosphine ligand Tol-P-Phos has been synthesized and the structure of the complex of $(R)$-Tol-PPhos oxide with (-)-dibenzoyl-L-tartaric acid [(-)-DBT] was determined by single crystal X-ray diffraction. The ruthenium complex of Tol-P-Phos, $\mathrm{Ru}(R$-Tol-P-Phos $)\left(\mathrm{C}_{6} \mathrm{H}_{6}\right) \mathrm{Cl}_{2}$, has been found to be a highly active and enantioselective catalyst in the asymmetric hydrogenation of $\beta$-ketoesters (up to $98.2 \%$ e.e.). The catalyst is also found to be air-stable even in solution.
\end{abstract}

Key words: asymmetric catalysis, hydrogenation, dipyridylphosphine ligands, ruthenium complex, $\beta$-ketoester

The search for new chiral ligands is an ongoing process in the field of asymmetric synthesis. ${ }^{1}$ Although more than a thousand chiral nonracemic diphosphines have been synthesized and the efficiency of catalysts derived from these ligands have been established, ${ }^{1,2}$ the possibility of discovering catalysts with improved utility, activity, and selec- tivity by designing new ligands remains to be an area of active research.

Over the past two decades, tremendous success has been achieved in the use of chiral arylphosphine ligands such as BINAP, BIPHEP, MeO-BIPHEP, and DuPhos, etc. in Rhor Ru-catalyzed asymmetric hydrogenation reactions. ${ }^{1}$ As an effort to expand the scope of the arylphosphine ligands and their application in homogeneous catalysis, transition-metal complexes containing pydridylphosphine ligands have been synthesized and tested in homogeneous catalysis. ${ }^{3}$ Unfortunately, the tested complexes were found to be inactive in the homogeneous hydrogenations owing to the pyridyl group which coordinated to the metal center and rendered the complex coordinately saturated. ${ }^{4}$ By preventing the coordination of the pyridyl groups via the use of bulky substituents, we found that the resulting rhodium(I) complex was effective for the hydrogenation of aldehydes, olefins, and imines. ${ }^{5}$
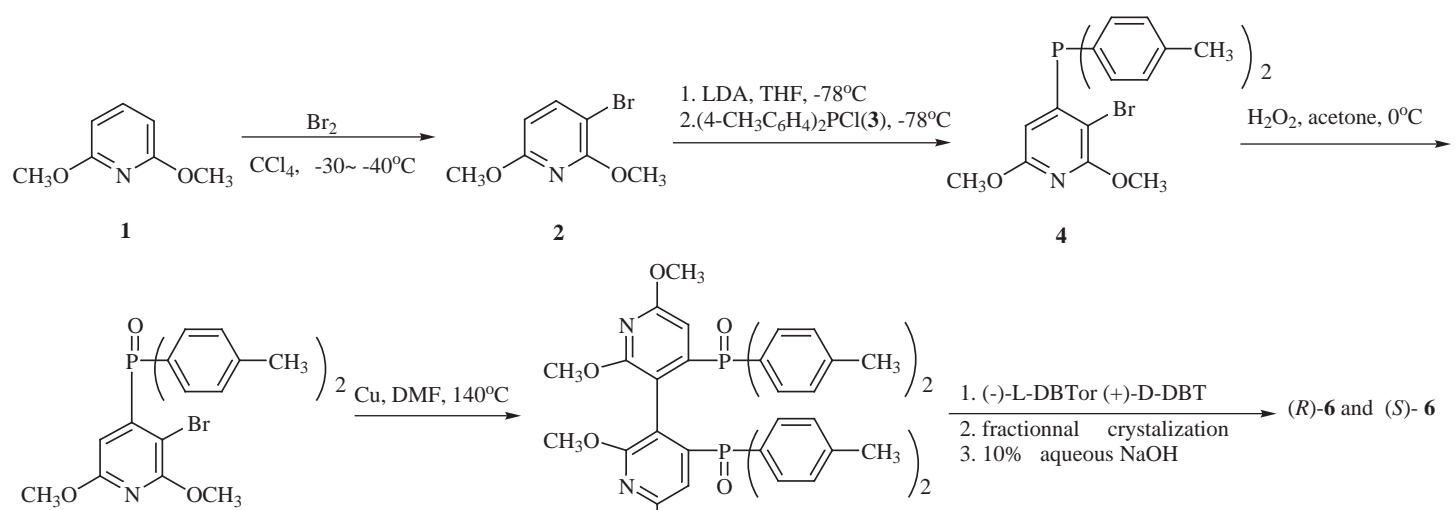<smiles>COc1cc(P(C)c2ccc(C)cc2)c(-c2c(P(C)(=O)c3ccc(C)cc3)cc(OC)nc2OC)c(OC)n1</smiles>

1. (-)-L-DBTor (+)-D-DBT 2. fractionnal crystalization $\longrightarrow(R)-6$ and $(S)-6$ 3. $10 \%$ aqueous $\mathrm{NaOH}$

5

$( \pm)-6$

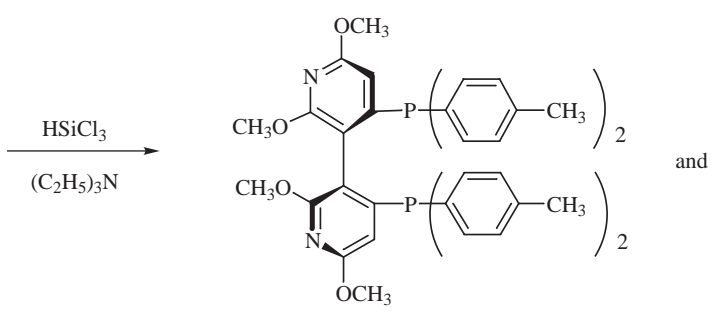

(R)-Tol-P-Phos<smiles>COc1ccc(P(c2ccccc2)c2cc(OC)nc(OC)c2-c2c(P(c3ccc(C)cc3)c3ccc(C)cc3)cc(OC)nc2OC)cc1</smiles>

(S)-Tol-P-Phos

Scheme Synthesis of Tol-P-Phos 


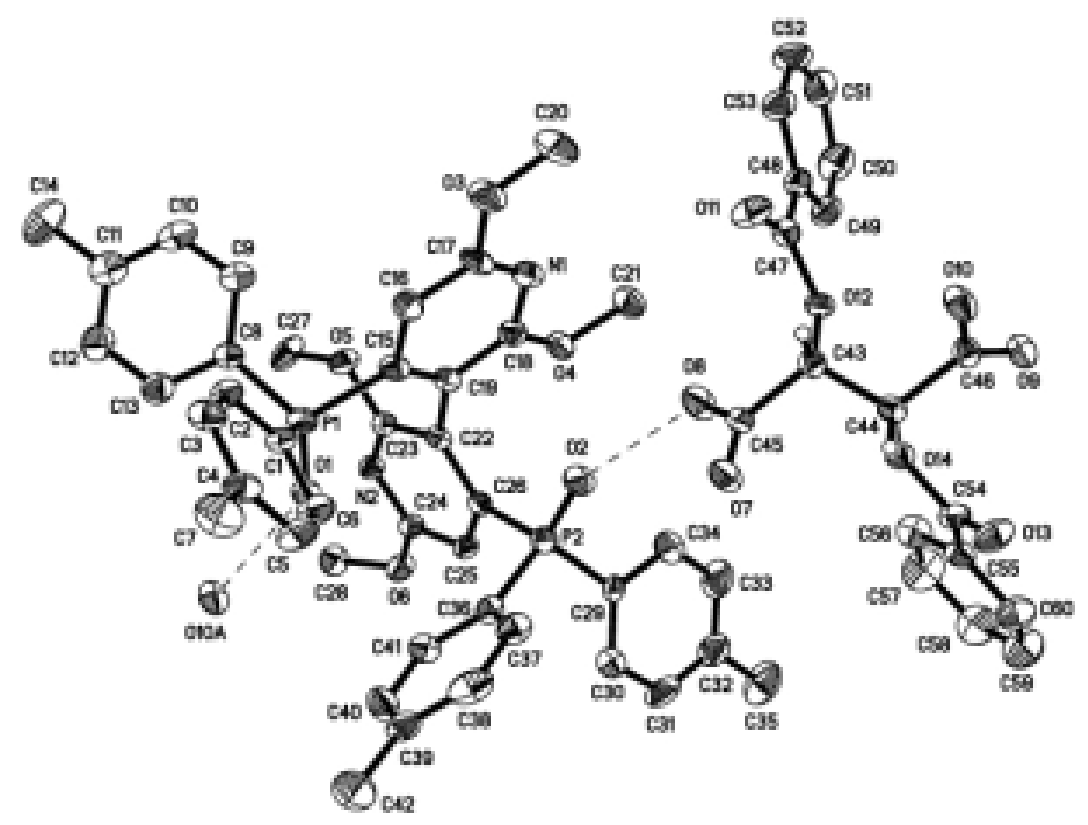

Figure ORTEP Drawing of the Complex $(R)-(+)-6-(-)-D B T$ with Numbering Schemes. Selected distances $(\AA)$ and angles (deg): C(19) $\mathrm{C}(22)=1.502(5), \mathrm{P}(1)-\mathrm{C}(15)=1.806(3), \mathrm{P}(2)-\mathrm{C}(29)=1.796(3), \mathrm{P}(1)-\mathrm{O}(1)=1.486(2), \mathrm{P}-(2)-\mathrm{O}(2)=1.487(2), \mathrm{O}(1) \cdots \mathrm{O}$ $(10 \mathrm{~A})=2.530, \mathrm{O}(2) \cdots \mathrm{O}(8)=2.487$

Inspired by the success of the modified pyridylphosphine ligand, we have developed a chiral dipyridylphosphine ligand 2,2',6,6'-tetramethoxy-4,4'-bis(diphenylphosphino)-3,3'-bipyridine (P-Phos), ${ }^{6}$ which was found to be very effective in the Ru catalyzed asymmetric hydrogenation of 2-(6'-methoxy-2'-naphthyl)propenoic acid to give the nonsteroidal anti-inflammatory drug naproxen. ${ }^{6,7}$ In this paper, we report the synthesis, characterization and application of a new dipyridylphosphine ligand, 2,2',6,6'-tetramethoxy-4,4'-bis[di( $p$-tolyl)phosphino]-3,3'-bipyridine (Tol-P-Phos).

The synthetic route of Tol-P-Phos is outlined in the Scheme. The slow addition of bromine to commercially available $\mathbf{1}$ in $\mathrm{CCl}_{4}$ between $-30{ }^{\circ} \mathrm{C}$ to $-40^{\circ} \mathrm{C}$ gave 3-bromo-2,6-dimethoxypyridine (2) in $76 \%$ yield. ${ }^{8}$ The regioselective lithiation ${ }^{9}$ of $\mathbf{2}$ with lithium diisopropylamide (LDA) in THF at $-78^{\circ} \mathrm{C}$, followed by the addition of di(4methylphenyl)phosphine chloride $(\mathbf{3})$ provided 3-bromo2,6- dimethoxy-4-di( $p$-methylphenyl)phosphinopyridine $(4,55 \%$ yield), while 3 was prepared according to the literature method in $73 \%$ yield. ${ }^{10}$ Oxidation of $\mathbf{4}$ with hydrogen peroxide in acetone at $0{ }^{\circ} \mathrm{C}$ produced 5 in $99 \%$ yield. The racemic dipyridylphosphine oxide $\mathbf{6}$ was obtained via Ullmann coupling ${ }^{11}$ of 5 .

The resolution of racemate $( \pm)$ - 6 was achieved by the use of enantiomers of DBT. ${ }^{12}$ When a solution of $(2 R, 3 R)$ $(-)$-DBT in ethyl acetate was added to a boiling solution of racemic compound $\mathbf{6}$ in chloroform, a 1:1 complex of $(+)-6$ and (-)-DBT [(+)-6-(-)-DBT] precipitated as a crystalline solid. X-ray structure analysis (Figure) re- vealed that the crystals are built up of infinite closepacked chains in which equimolar (+)-6 and (-)-DBT are connected in a regularly alternating way through two inter-molecular hydrogen bonds between oxygen atoms $[\mathrm{O}(1)$ and $\mathrm{O}(2)]$ of the $\mathrm{P}=\mathrm{O}$ groups in compound $\mathbf{6}$ and hydrogen atoms of the $\mathrm{COOH}$ groups of DBT.

The low solubility of complex (+)-6-(-)-DBT is attributable to such a linear polymeric structure. From the internal comparison with $(2 R, 3 R)-(-)$-DBT, the absolute configuration of (+)-6 was determined to be $R$. Subsequent decomposition of complex (+)-6-(-)-DBT with aq. $\mathrm{NaOH}$ provided enatiomerically pure $(R)-(+)-6$ in $91 \%$ yield based on the ( \pm )-6 used. $(S)-(-)-6$ was recovered from the mother liquor of the recrystallization by treatment with aq. $\mathrm{NaOH}$. This crude product could be further purified via the formation of the complex with (+)-DBT. Thus, both $(R)-(+)-6$ and $(S)-(-)-6$ enatiomers were effectively obtained by choosing the handedness of the resolving agents. Reduction of enantiomerically pure 6 with trichlorosilane in the presence of triethylamine led to the targeted enantiomers of atropisomeric ligands 7 (92\% yield), the structure of which was confirmed by ${ }^{1} \mathrm{H},{ }^{13} \mathrm{C},{ }^{31} \mathrm{P}$ NMR, and elemental analysis.

Using Mashima et al's method, ${ }^{13} \mathrm{Ru}(R$-Tol-PPhos) $\left(\mathrm{C}_{6} \mathrm{H}_{6}\right) \mathrm{Cl}_{2}$ (8) was prepared by mixing $\left[\mathrm{RuCl}_{2}\left(\mathrm{C}_{6} \mathrm{H}_{6}\right)\right]_{2}$ with $R$-Tol-P-Phos in an 8:1 mixture of ethanol-benzene and the complex was isolated as a reddish brown solid. The structure of the complex was characterized by ${ }^{1} \mathrm{H}$, and ${ }^{31} \mathrm{P}$ NMR..${ }^{14}$ 
Table 1 Asymmetric Hydrogenation of $\beta$-Ketoesters Catalyzed by $8^{\text {a }}$

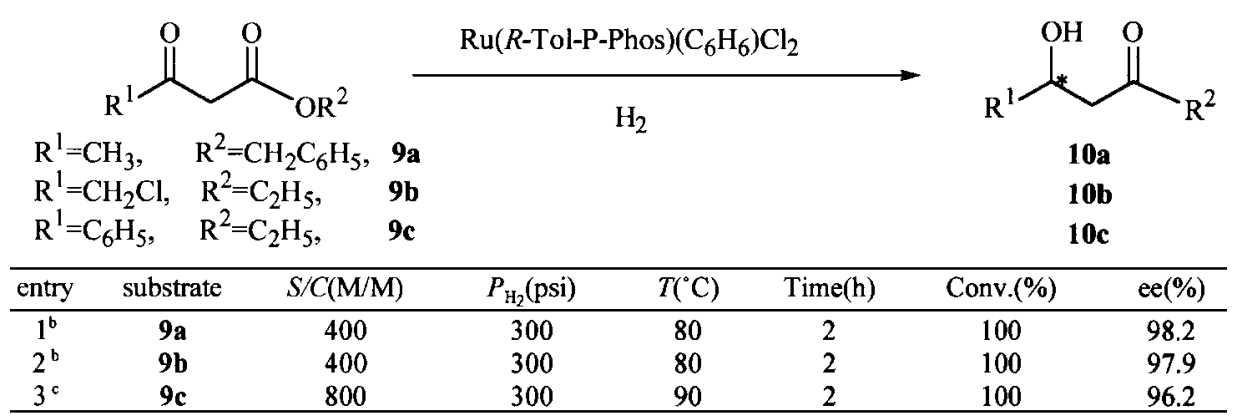

a Reaction conditions: $200 \mathrm{mg}$ substrate; substrate concentration $=1.78-2.38 \mathrm{M}$ in $\mathrm{EtOH} / \mathrm{CH}_{2} \mathrm{Cl}_{2}$, The substrate and catalyst were added to the stainless steel autoclave under $\mathrm{N}_{2}$ and the solvents were degassed and dried prior to use.

${ }^{b}$ The convertion yield and the ee were determined by chiral GC with a Chrompack Chirasil-DEX $\mathrm{CB}$ columns after converting the products to the corresponding acetyl derivatives.

${ }^{\mathrm{c}}$ The conversion yield and the ee were determined by $500 \mathrm{MHz}{ }^{1} \mathrm{H}$ NMR and HPLC analysis (Chiralcel OD column).

8 was found to be a highly effective catalyst for the asymmetric hydrogenation of $\beta$-ketoesters (Table 1). The reactions proceeded smoothly at $80-90{ }^{\circ} \mathrm{C}$ and under $300 \mathrm{psi}$ of $\mathrm{H}_{2}$ in two hours and the ee value is up to $98.2 \%$ (entry $1)$.

The hydrogenation of $\mathbf{9 c}$ leads to a useful pharmaceutical intermediate, $(S)$-3-hydroxy-3-phenyl propionate $(\mathbf{1 0 c}) .^{15}$ Table 2 indicates that the rate and enantioselectivity of this reaction were influenced by the choice of solvent, $\mathrm{H}_{2}$ pressure and the molar ratio of substrate to catalyst (S/C). The mixed solvent of EtOH $-\mathrm{CH}_{2} \mathrm{Cl}_{2}(1: 1)$ and lower $\mathrm{H}_{2}$ pressure are favorable for higher enatioselectivity. Entry 11-13 were carried out in a larger scale (30 g substrate) and the results indicated that no substantial decrease of ee (95.9\% ee, entry 11) with high S/C ratio. Although enatioselectivity is a major concern in modern asymmetric synthesis, the reactivity and productivity are also important factors of consideration in determining the commercial feasibility of a reaction. ${ }^{2 e}$ Thus the demonstration of carrying out the reaction at high $\mathrm{S} / \mathrm{C}$ ratio without losing enantioselectivity was encouraging. Other desirable features of a good catalyst system include the ease of catalyst preparation and handling as well as the operational simplicity of the experimental procedures. A usual problem associated with the use of noble metal phosphine catalysts is the air-sensitivity of the catalysts. The oxidation of the active catalysts by trace amounts of air in the reaction system often makes irreproducible results in many reactions. This problem is even more severe in industrial applications in which the rigorous de-gassing is usually more difficult than the laboratory-scale operations. Therefore, it is highly desirable to develop effective catalysts with good air-stability. In this study we were delighted to find that the $\mathrm{Ru}(R$-Tol-P-Phos $)\left(\mathrm{C}_{6} \mathrm{H}_{6}\right) \mathrm{Cl}_{2}$ catalyst system to be highly air-stable. In a simple stability test we found that when the substrate $(\mathbf{9 c})$ and the $\mathrm{Ru}(R$-Tol-P-Phos) catalyst were added to the stainless steel autoclave in air and when the solvents were not degassed and dried prior to use, the activity and enatioselectivity of the catalyst $(\mathbf{8})$ remained to be unchanged ( $96.4 \%$ ee, entry 14$)$ from the air-proved system $(96.2 \%$ ee, entry 8$)$. Further investigation showed that the activity and enatioselectivity of $\mathbf{8}$ remained to be the same even its solution in $\mathrm{EtOH}$ and $\mathrm{CH}_{2} \mathrm{Cl}_{2}$ were stirred for 10 hours under air prior to its application (95.7\% ee, entry 15$)$. These results compared favorably with those obtained from the use of $\mathrm{Ru}(R$-Binap) $\left(\mathrm{C}_{6} \mathrm{H}_{6}\right) \mathrm{Cl}_{2}$ as catalyst precursor in a side by side comparison study.

The air-stability of $\mathbf{8}$ was also supported by a ${ }^{31} \mathrm{P}$ NMR study (Figure 2). After the catalyst solution was exposed to air for $10 \mathrm{~h}$, its ${ }^{31} \mathrm{P}$ NMR spectrum showed no variation in comparison with that determined under $\mathrm{N}_{2}\left[\mathrm{CDCl}_{3}, 500\right.$ $\mathrm{MHz}, \delta 31.15(\mathrm{~d}, J=62.71 \mathrm{~Hz}), 38.28(\mathrm{~d}, J=62.71$ $\mathrm{Hz})] .{ }^{14}$ These results showed excellent potential for the practical applications of the P-Phos type ligands in asymmetric catalytic reactions.

In conclusion, we have developed a new dipyridylphosphine ligand and its Ru complex $\mathbf{8}$ has been found to be a highly effective catalyst in the asymmetric hydrogenation of $\beta$-ketoesters. It is of high interest to note that $\mathbf{8}$ is stable to air, which makes the experiments convenient to operate and also shows a good potential for its industrial application.

\section{Acknowledgement}

We thank the Hong Kong Research Grants Council (Project number PolyU 5177/99P) and The Hong Kong Polytechnic University (ASD) for financial support of this study. 
Table 2 The Effect of Reaction Conditions on the Asymmetric Hydrogenation of 9c Catalyzed by 8

\begin{tabular}{|c|c|c|c|c|c|c|}
\hline Entry & Solvent(v/v) & $S / C(\mathrm{M} / \mathrm{M})$ & $P_{\mathrm{H}_{2}}$ (psi) & Time(h) & Conv.(\%) & ee(\%) (config.) \\
\hline $1^{a, c}$ & $\mathrm{EtOH}$ & 800 & 500 & 12 & 100 & $95.5(\mathrm{~S})$ \\
\hline $2^{a, c}$ & $\begin{array}{c}\mathrm{EtOH} / \mathrm{CH}_{2} \mathrm{Cl}_{2} \\
1: 1\end{array}$ & 800 & 500 & 12 & 100 & $96.0(\mathrm{~S})$ \\
\hline $3^{a, c}$ & $\begin{array}{c}\mathrm{EtOH} / \mathrm{CH}_{2} \mathrm{Cl}_{2} \\
1: 2\end{array}$ & 800 & 500 & 12 & 100 & $95.8(\mathrm{~S})$ \\
\hline $4^{\mathrm{a}, \mathrm{c}}$ & $\begin{array}{c}\mathrm{EtOH} / \mathrm{CH}_{2} \mathrm{Cl}_{2} \\
1: 3\end{array}$ & 800 & 500 & 12 & 100 & $90.9(\mathrm{~S})$ \\
\hline $5^{a, c}$ & $\begin{array}{c}\text { EtOH/THF } \\
1: 1\end{array}$ & 800 & 500 & 12 & 100 & $94.7(\mathrm{~S})$ \\
\hline $6^{\mathrm{a}, \mathrm{c}}$ & $\begin{array}{c}\text { EtOH/Tolune } \\
1: 1\end{array}$ & 800 & 500 & 12 & 90.8 & $85.2(\mathrm{~S})$ \\
\hline $7^{a, c}$ & $\begin{array}{c}\mathrm{EtOH} / \mathrm{CH}_{2} \mathrm{Cl}_{2} \\
1: 1\end{array}$ & 800 & 300 & 1.5 & 95.4 & $95.6(\mathrm{~S})$ \\
\hline $8^{a, c}$ & $\begin{array}{c}\mathrm{EtOH} / \mathrm{CH}_{2} \mathrm{Cl}_{2} \\
1: 1\end{array}$ & 800 & 300 & 2 & 100 & $96.2(S)(92.0)^{\mathrm{g}}$ \\
\hline $9^{a, c}$ & $\begin{array}{c}\mathrm{EtOH} / \mathrm{CH}_{2} \mathrm{Cl}_{2} \\
1: 1\end{array}$ & 800 & 1000 & 2 & 100 & $94.7(\mathrm{~S})$ \\
\hline $10^{\mathrm{a}, \mathrm{c}}$ & $\begin{array}{c}\mathrm{EtOH} / \mathrm{CH}_{2} \mathrm{Cl}_{2} \\
1: 1\end{array}$ & 2400 & 350 & 15 & 100 & $96.1(\mathrm{~S})$ \\
\hline $11^{b, c}$ & $\begin{array}{c}\mathrm{EtOH} / \mathrm{CH}_{2} \mathrm{Cl}_{2} \\
1: 1\end{array}$ & 5000 & 350 & 15 & 100 & $95.9(\mathrm{~S})$ \\
\hline $12^{b, c}$ & $\begin{array}{c}\mathrm{EtOH} / \mathrm{CH}_{2} \mathrm{Cl}_{2} \\
1: 1\end{array}$ & 7500 & 350 & 15 & 90 & 91.3(S) \\
\hline $13^{b, c}$ & $\begin{array}{c}\mathrm{EtOH} / \mathrm{CH}_{2} \mathrm{Cl}_{2} \\
1: 1\end{array}$ & 7500 & 350 & 24 & 95 & $94.7(S)$ \\
\hline $14^{\text {add }}$ & $\begin{array}{c}\mathrm{EtOH} / \mathrm{CH}_{2} \mathrm{Cl}_{2} \\
1: 1\end{array}$ & 800 & 300 & 3 & 100 & $96.4(\mathrm{~S})(90.0)^{\mathrm{g}}$ \\
\hline $15^{\text {a.e }}$ & $\begin{array}{c}\mathrm{EtOH} / \mathrm{CH}_{2} \mathrm{Cl}_{2} \\
1: 1\end{array}$ & 800 & 300 & 3 & $100(95.5)$ & $95.7(S)(66.6)^{\mathrm{g}}$ \\
\hline
\end{tabular}

a90 ${ }^{\circ} \mathrm{C} ; 200 \mathrm{mg}$ substrate; substrate concentration $=1.73 \mathrm{M}$.

${ }^{\mathrm{b}} 90{ }^{\circ} \mathrm{C} ; 30 \mathrm{~g}$ substrate; substrate concentration $=4.11 \mathrm{M}$.

${ }^{c}$ The substrate and catalyst were added to the stainless steel autoclave under $\mathrm{N}_{2}$ and the solvents were degassed and dried prior to use.

${ }^{\mathrm{d}}$ The substrate and catalyst were added to the stainless steel autoclave in air and the solvents were not degassed and dried prior to use.

e The catalysts solution in $\mathrm{EtOH}$ and $\mathrm{CH}_{2} \mathrm{Cl}_{2}$ were stirred for 10 hours under air before the addition of substrate and $\mathrm{H}_{2}$.

${ }^{\mathrm{f}}$ The absolute configurations were assigned according to ref. $16{ }^{\mathrm{g}}$ The numbers in bracket were obtained by using $\mathrm{Ru}(R$-Binap $)\left(\mathrm{C}_{6} \mathrm{H}_{6}\right) \mathrm{Cl}_{2}$ as catalyst under the same reaction conditions.

\section{References and Notes}

(1) (a) Noyori, R. In Asymmetric Catalysis in Organic Synthesis; Wiley: New York, 1993. (b) Ojima, I. In Catalytic Asymmetric Synthesis; 2nd Ed.; Wiley: New York, 2000. (c) Brunner, H. Synthesis 1988, 645. (d) Bhaduri, S.; Mukesh, D. In Homogeneous Catalysis Mechanisms and Industrial Applications; Wiley: New York, 2000. (e) Lin, G.-Q.; Li, Y.-M.; Chan, A. S. C. In Principles and Applications of Asymmetric Synthesis; Wiley: New York, 2001.

(2) (a) Knowles, W. S. Acc. Chem. Res. 1983, 16, 106. (b) Noyori, R.; Takaya, H. Acc. Chem. Res. 1990, 23, 345. (c) Noyori, R. Science 1990, 248, 1194. (d) Chan, A. S. C.; Hu, W.; Pai, C.-C.; Lau, C.-P. J. Am. Chem. Soc. 1997, 119, 9570. (e) Noyori, R.; Ohkuma, T.; Angew. Chem. Int. Ed. 2001, 40, 40.

(3) (a) Newkome, G. R. Chem. Rev. 1993, 93, 2067. (b) Brunner, H.; Bublak, P. Synthesis 1995, 36. (c) Yang, H.; Alvarez, M.; Lugan, N.; Mathieu, R. J. J. Chem. Soc., Chem. Commun. 1995, 1721. (d) Fell, B.; Papadogianakis, G. J. Mol. Catal. 1991, 66, 143.
(4) Kurtev, K.; Bibola, D.; Jones, R. A.; Cole-Hamilton, D. J.; Wilkinson, G. J. Chem. Soc., Dalton. Trans. 1990, 55.

(5) (a) Chan, A. S. C.; Chen, C. C.; Cao, R. Organometallics 1997, 16, 3469. (b) Hu, W.; Pai, C. C.; Chen, C. C.; Xue, G.; Chan, A. S. C. Tetrahedron: Asymmetry 1998, 9, 3214. (c) Hu, W.; Chen, C. C.; Xue, G. Chan, A. S. C. Tetrahedron: Asymmetry 1998, 9, 4183.

(6) Pai, C.-C.; Lin, C.-W.; Lin, C.-C.; Chen, C.-C.; Chan, A. S. C.; Wong, W. T. J. Am. Chem. Soc. 2000, 122, 11513.

(7) Harrington, P. J.; Lodewijk, E. Org. Process Res. Dev. 1997, 1,72 .

(8) Subhash, K. P.; Edward, B. R. Heterocycles 1998, 27, 2643.

(9) (a) Gu, Y. G.; Erol, B. K. Tetrahedron Lett. 1996, 37, 2565. (b) Gribble, G. W.; Saulnier, M. G. Heterocycles 1993, 35, 151.

(10) Casalnuovo, A. L.; RajanBabu, T. V.; Ayers, T. A.; Warren, T. H. J. Am. Chem. Soc. 1994, 116, 9869.

(11) Fanta, P. E. Synthesis 1974, 9.

(12) (a) Takaya, H.; Akutagawa, S.; Noyori, R. Org. Synth. 1988, 67, 20. (b) Zhang, X.; Mashima, K.; Koyano, K.; Sayo, N.;Kumobayashi, H.; Akutagawa, S.; Takaya, H. J. Chem. Soc. Perkin Trans. 1 1994, 2309. 
(13) Mashima, K.; Kusano, K.; Sato, N.; Matsumura, Y.; Nozaki, K.; Kumobayashi, H.; Sayo, N.; Hori, Y.; Ishizaki, T.; Akutagawa, S.; Takaya, H. J. Org. Chem. 1994, 59, 3064.

(14) Spectral data for 8: ${ }^{1} \mathrm{H}$ NMR $\left(\mathrm{CDCl}_{3}, 500 \mathrm{MHz}\right): \delta 2.31(\mathrm{~s}, 6 \mathrm{H}$, $\left.\mathrm{PhCH}_{3}\right), 2.35$ (s, 6H, $\left.\mathrm{PhCH}_{3}\right), 3.48\left(\mathrm{~s}, 3 \mathrm{H}, \mathrm{OCH}_{3}\right), 3.58(\mathrm{~s}, 3 \mathrm{H}$, $\left.\mathrm{OCH}_{3}\right), 3.61\left(\mathrm{~s}, 3 \mathrm{H}, \mathrm{OCH}_{3}\right), 3.73\left(\mathrm{~s}, 3 \mathrm{H}, \mathrm{OCH}_{3}\right), 5.75(\mathrm{~s}, 6 \mathrm{H}$, $\left.\mathrm{C}_{6} H_{6}\right), 5.94(\mathrm{~d}, \mathrm{~J}=12.0 \mathrm{~Hz}, 1 \mathrm{H}, \mathrm{Py} H), 6.38(\mathrm{~d}, \mathrm{~J}=10.5 \mathrm{~Hz}$, $1 \mathrm{H}, \mathrm{Py} H)$, 7.18-7.20 (m, 6H, $\mathrm{Ph} H)$, 7.29-7.45 (m, 10H, $\mathrm{Ph} H)$. ${ }^{31} \mathrm{P} \mathrm{NMR}\left(\mathrm{CDCl}_{3}, 500 \mathrm{MHz}\right): \delta 31.15(\mathrm{~d}, \mathrm{~J}=62.71 \mathrm{~Hz}), 38.26$ $(\mathrm{d}, \mathrm{J}=62.71 \mathrm{~Hz})$
(15) Kumar, A.; Ner, D. H.; Dike, S. Y. Tetrahedron Lett. 1991, 32, 1901.

(16) Noyori, R.; Ohkuma, T.; Kitamura, M. J. Am. Chem. Soc. 1987, 109, 5856.

Article Identifier:

1437-2096,E;2001,0,SI,1050,1054,ftx,en;Y08201ST.pdf 